Abstract

\title{
Plant Biostimulants for Enhanced Sustainability of High-Residue Farming Systems ${ }^{\dagger}$
}

\author{
Diana Constantinescu-Aruxandei ${ }^{1}\left(\mathbb{D}\right.$, Steven Brooks $^{2}$, Alina Nicolescu ${ }^{3}\left(\mathbb{D}\right.$, , Sergey Shaposhnikov ${ }^{4}$, \\ Florentina Georgescu ${ }^{5}$, Liliana Adriana Pairault ${ }^{6}$, Luminița Marin ${ }^{3}$ (D) Călin Deleanu ${ }^{3}$ (D) and Florin Oancea ${ }^{1, *}$
}

1 National Institute for Research \& Development in Chemistry and Petrochemistry-ICECHIM, Spl. Independentei 202, Sector 6, 060201 Bucharest, Romania; diana.constantinescu@icechim.ro

2 Norway Institute for Water Research-NIVA, Økernveien 94, 0579 Oslo, Norway; steven.brooks@niva.no

3 Petru Poni Institute for Macromolecular Chemistry, Grigore Ghica Voda Alley 41A, 700487 Iasi, Romania; alina@icmpp.ro (A.N.); lmarin@icmpp.ro (L.M.); calin.deleanu@yahoo.com (C.D.)

4 Norgenotech AS, Totenvegen 2049, 2848 Skreia, Norway; sas@norgenotech.no

5 Enpro Soctech, Elefterie Street 31, Sector 5, 050525 Bucharest, Romania; fg@yahoo.com

6 Amia Import-Export, Gorunului Str. 7, 75100 Otopeni, Romania; liliana.pairault@amia.ro

* Correspondence: florin.oancea@icechim.ro

+ Presented at the 17th International Symposium "Priorities of Chemistry for a Sustainable Development" PRIOCHEM, Bucharest, Romania, 27-29 October 2021.

Keywords: high-residue farming system; plant biostimulants; Trichoderma; Paenibacillus; chitosan hydrogel; strigolactone mimics; nanoselenium; microalgae extract; ecotoxicology

check for updates

Citation: Constantinescu-Aruxandei, D.; Brooks, S.; Nicolescu, A.; Shaposhnikov, S.; Georgescu, F.; Pairault, L.A.; Marin, L.; Deleanu, C.; Oancea, F. Plant Biostimulants for Enhanced Sustainability of High-Residue Farming Systems. Chem. Proc. 2022, 7, 16. https:// doi.org/10.3390/chemproc 2022007016

Published: 1 March 2022

Publisher's Note: MDPI stays neutral with regard to jurisdictional claims in published maps and institutional affiliations.

Copyright: (C) 2022 by the authors. Licensee MDPI, Basel, Switzerland. This article is an open access article distributed under the terms and conditions of the Creative Commons Attribution (CC BY) license (https:// creativecommons.org/licenses/by/ $4.0 /)$.
Besides multiple benefits, high-residue farming systems have drawbacks: delayed development of the plant in early stages, nutrient availability, and enhanced risks for soil-borne diseases [1]. These drawbacks are targeted by the second-generation plant biostimulants delivered in the frame of the RO-NO project STIM4 ${ }^{+}$. Plant biostimulants represent an emerging agricultural input class that protects plants against abiotic stress, enhances/benefits nutrients uptake, and improves yield quality. The STIM4 ${ }^{+}$project objectives are: (i) to develop plant biostimulants intended to improve the resource use efficiency of high-residue grown vegetables; (ii) to assess and to characterize the new plant biostimulants effects on vegetables and rhizosphere microorganism; and (iii) to investigate the safety and environmental impact of the newly developed plant biostimulants.

Vegetable cultivation in a hairy vetch mulch is the targeted high-residues farming system [2]. The plant biostimulants developed in the frame of RO-NO 540 STIM4 ${ }^{+}$project intend to compensate for the drawbacks of this farming system. These plant biostimulants are based on: microbial plant biostimulants that respond to rhizosphere endo-signals, strigolactone mimics, chitosan hydrogel, selenium nanoparticles, and microalgae extract containing betaine and polyamines. The STIM $4^{+}$project targets the optimal exploitation of the agrotechnical benefits of selenium biofortification by the following key objectives: (i) a better understanding of the plant biostimulants and of the effects of their active ingredients on vegetables and rhizosphere microbiome, which will be used for (ii) the optimization of the proposed plant biostimulants and (iii) the improvements of the application method (timing, dose) for an enhanced eco-efficiency and increased profitability of the field-grown vegetables.

The outcome of the STIM4+ project is an integrated agro-bio-nano-technology, which determines phytonutrients bio-enhancement and selenium biofortification on vegetables and produces more with less in the area with selenium deficit in soil. Both Romania [3,4] and Norway [5,6] are among countries with selenium deficits in soils. Even though it is not recognized as a micronutrient essential for plants, selenium is needed to express plant tolerance to abiotic stress $[7,8]$, amplified by climatic changes. In the deficit area, the food 
chain needs to be supplemented/biofortified with selenium. Due to the narrow physiological window, selenium biofortification (through plant treatment) is better than direct supplementation. One illustrative example of how better knowledge and understanding of mechanisms leads to enhanced agrotechnical benefits of the selenium biofortification process is presented in Figure 1. Selenium exerts epigenetic effects, also due to activation of betaine homocysteine methyltransferase (BMHT), a key enzyme for one-carbon metabolism and S-Adenosyl methionine restoration [3]. The application of exogenous betaine is intended to accelerate the formation of methionine from homocysteine by providing BHMT additional substrate $[4,5]$. Active ingredients of the plant biostimulants applied concomitantly sustain the S-Adenosyl methionine pool by activating the methionine adenosine transferase (MAT) [6,7]. The epigenetic effect of selenium was recently demonstrated to be involved in the enhanced tolerance of maize plants to water stress [8]. Our project intends to determine such an epigenetic effect on vegetables (tomatoes and pepper) grown into hairy vetch mulch and treated with plant biostimulants.

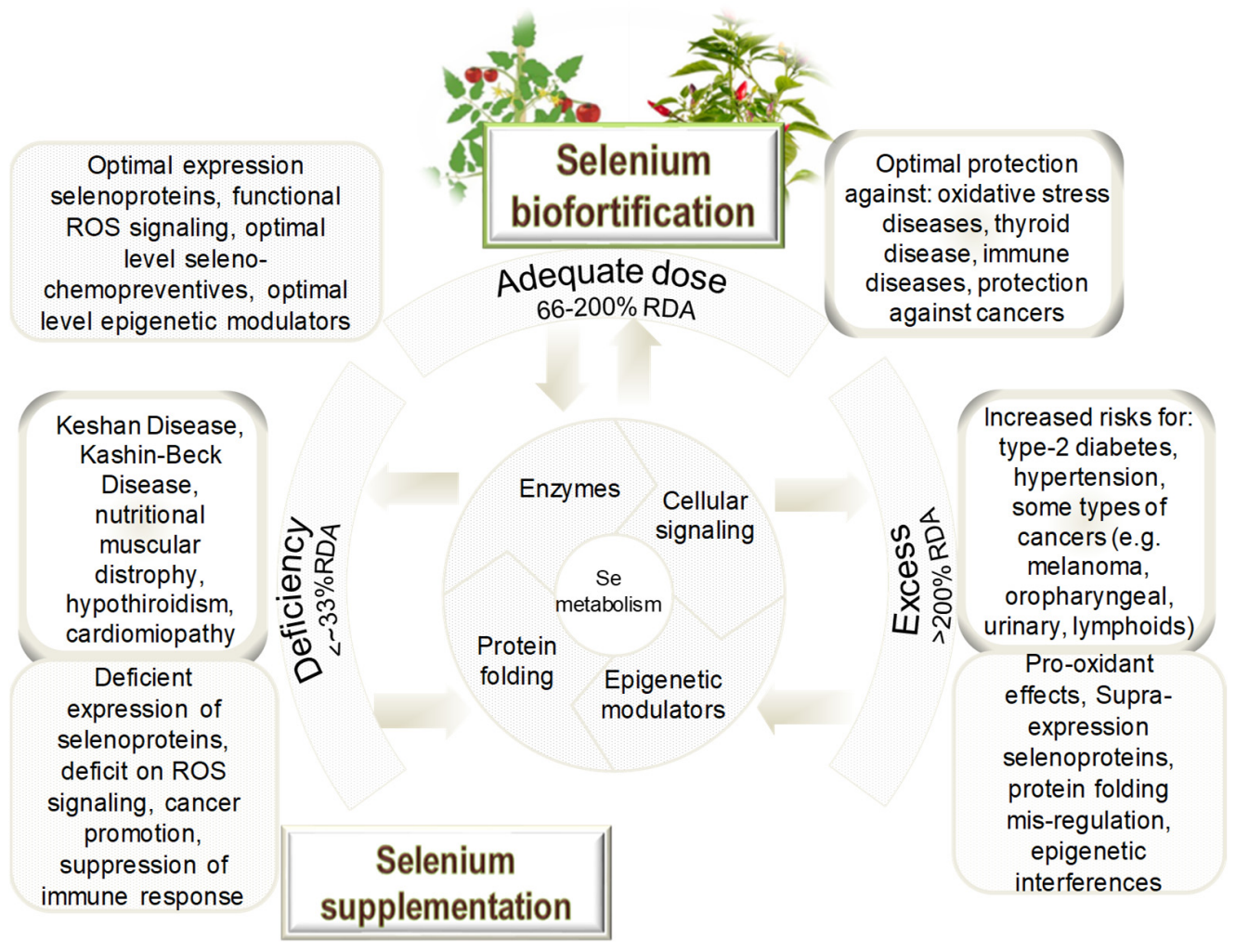

Figure 1. The physiological window of selenium. The U-shape relationship between selenium and disease status limits selenium supplementation to lower than optimal selenium status subjects. The selenium (bio)fortification should present a lower risk of supplementation on subjects with Se optimal or supra-optimal status. Modified from Constantinescu-Aruxandei et al. [9].

The application technologies are designed to exploit the functions of strigolactones as exo-signals for the better harnessing of the beneficial microbiome and as a cue for harmful organisms (e.g., to induce suicidal germination of parasitic plants).

The ongoing STIM 4+ project activities refer to the delivery of (i) selected strains that respond to strigolactones, used to produce the microbial plant biostimulants; (ii) integrated process to produce zero-valent biogenic nanoselenium, as representative inorganic plant biostimulants and concentrated microbial microalgae extracts, as organic plant biostimulants; (iii) optimized synthesis reactions to produce strigolactone mimics, with enhanced exo-signal activities; and (iv) chitosan hydrogel, for application on the plant residues and formulation of the plant biostimulants. These results will be further integrated with the application technology. The safety and environmental impact of the newly developed 
products are determined by state-of-the-art $3 \mathrm{R}$ techniques applied to soil solution samples collected in situ by suction lysimeters.

The integrated application of the plant biostimulants developed in the frame of the STIM 4+ project enhances the sustainability of the high-residues farming system based on hairy vetch. Nutrient use efficiency and plant tolerance to the abiotic stress are improved due to applying the new plant biostimulants. Crop quality is enhanced due to secondary metabolism activation and higher accumulation of bioactive compounds in the edible yield.

Author Contributions: Conceptualization, D.C.-A. and F.O.; methodology, F.O.; software, S.S.; validation, S.B., A.N. and L.M.; formal analysis, S.S.; investigation, L.A.P.; resources, F.O.; data curation, C.D.; writing-original draft preparation, D.C-A.; writing-review and editing, S.B. and F.G.; visualization, S.B.; supervision, F.O.; project administration, D.C.-A.; funding acquisition, F.O. All authors have read and agreed to the published version of the manuscript.

Funding: This work was supported by the project RO-NO-2019-540, “Integrated use of the next generation plant biostimulants for enhanced sustainability of field vegetable high residue farming systems-STIM4 ${ }^{+\prime}$, founded by UEFISCDI-EEA and Norway Grants.

Institutional Review Board Statement: Not applicable.

Informed Consent Statement: Not applicable.

Data Availability Statement: Not applicable.

Conflicts of Interest: The authors declare no conflict of interest.

\section{References}

1. Oancea, F.; Raut, I.; Sesan, T.E.; Cornea, P.C.; Badea-Doni, M.; Popescu, M.; Jecu, M.L. Hydro-gelified and film forming formulation of microbial plant biostimulants for crop residues treatment on conservation agriculture systems. Studia Univ. Vasile Goldis Arad. Life Sci. Ser. 2016, 26, 251.

2. Massantini, R.; Radicetti, E.; Frangipane, M.T.; Campiglia, E. Quality of Tomato (Solanum lycopersicum L.) Changes under Different Cover Crops, Soil Tillage and Nitrogen Fertilization Management. Agriculture 2021, 11, 106. [CrossRef]

3. Lăcătușu, R.; Oancea, F.; Stanciu-Burileanu, M.M.; Lăcătușu, A.; Lungu, M.; Stroe, V.M.; Manole, D.; Sicuia, O.; Iliescu, H.; Jinga, V. Selenium in the soilplant system from the south-eastern part of Romania. In Proceedings of the 15th World Fertilizers Congress, Bucharest, Romania, 29 August-2 September 2010; pp. 67-78.

4. Oancea, F.; Szabolcs, L.; Oancea, A.-O.; Lacatusu, R.; Abraham, B.; Stanciu-Burileanu, M.M.; Meszaros, A.; Lungu, M. Selenium biofortification biotechnologies of wheat grain in south-eastern part of Romania for a better human health. Studia Univ. Vasile Goldis Arad. Ser. Stiintele Vietii 2014, 24, 47.

5. Eich-Greatorex, S.; Sogn, T.A.; Ogaard, A.F.; Aasen, I. Plant availability of inorganic and organic selenium fertiliser as influenced by soil organic matter content and pH. Nutr. Cycl. Agroecosystems 2007, 79, 221-231. [CrossRef]

6. Govasmark, E.; Steen, A.; Strom, T.; Hansen, S.; Singh, B.R.; Bernhoft, A. Status of selenium and vitamin E on Norwegian organic sheep and dairy cattle farms. Acta Agric. Scand. Sect. A Anim. Sci. 2005, 55, 40-46. [CrossRef]

7. Sieprawska, A.; Kornaś, A.; Filek, M. Involvement of Selenium in Protective Mechanisms of Plants under Environmental Stress Conditions-Review. Acta Biol. Crac. Bot. 2015, 57, 9. [CrossRef]

8. Ahmad, R.; Waraich, E.A.; Nawaz, F.; Ashraf, M.Y.; Khalid, M. Selenium (Se) improves drought tolerance in crop plants-A myth or fact? J. Sci. Food Agric. 2016, 96, 372-380. [CrossRef] [PubMed]

9. Constantinescu-Aruxandei, D.; Frîncu, R.M.; Capră, L.; Oancea, F. Selenium analysis and speciation in dietary supplements based on next-generation selenium ingredients. Nutrients 2018, 10, 1466. [CrossRef] [PubMed] 